\title{
The Role of Input Enhancement in Teaching Compliments
}

\author{
Hossein Vahid Dastjerdi \\ English Department, University of Isfahan, Isfahan, Iran \\ Email: h_vahid@yahoo.com \\ Majid Farshid \\ The University of Isfahan, Isfahan, Iran \\ Email: farshidmajid@yahoo.com
}

\begin{abstract}
To date, research regarding the effectiveness of instruction on the development of interlanguage pragmatics has favored an explicit instruction of the speech acts. A question which has received scant attention is what kind of explicit instruction is more beneficial in a foreign language setting. The fact that speech acts reflect, for the most part, routinized language behavior helps learners because much of what is used in performing speech acts could be learned as prefabricated units. This study is an attempt to practically test this routinized nature of speech acts focusing on compliment giving. To this purpose, two groups were chosen as control and experimental groups and both were instructed by different procedures of input enhancement; the former was taught through Form Comparison procedure and the latter through explicit instruction using Wolfson and Manes (1980) formula of compliment giving. The result clearly indicated that the experimental group outperformed the control group in giving compliments, indicating once again that the routinized nature of speech acts could be utilized in helping learners develop their interlanguage pragmatics.
\end{abstract}

Index Terms - input enhancement, explicit instruction, compliment giving, interlanguage pragmatics, form comparison, focus on form

\section{INTRODUCTION}

Compared to areas such as grammar, lexis, or phonology, the effect of instruction on inter-language pragmatic development has been explored far less. In this regard, Kasper (1992) holds that the research that has been done to date does indicate that pragmatic development can be facilitated by instruction particularly when that instruction is of an explicit nature. What remains unclear, however, is what kind of explicit instruction is more likely to help second language learners develop their pragmatic competence more rapidly and better. Input enhancement seems to have the potential to shed light on this issue.

Input enhancement in second language acquisition (SLA) has been addressed in studies of form-focused instruction at morphosyntactic levels, known as Focus on Form (FonF) research. Following Sharewood Smith's (1993) definition of input enhancement, researchers experimentally manipulated instructional input on L2 structures in various ways: some form of corrective feedback with or without metalinguistic information, visual enhancement with the use of bold or italic face, and task manipulation directing learners to notice and attend to target structures. All these studies provided evidence that high levels of attention-drawing activities, as represented by presenting metalinguistic information and corrective feedback, are more helpful for learners in gaining the mastery of target-language structures than simple exposure to positive evidence. These findings thus provide the basis for theoretical verification of Schmidt's Noticing Hypothesis (1990), which states that conscious noticing is the necessary and sufficient condition for converting input to intake. In contrast to the rich array of input enhancement research into morphosyntactic features, there have been considerably fewer studies specially focusing on the role of input enhancement in developing L2 pragmatic competence. An increasing number of interlanguage pragmatics (ILP) researchers have become interested in exploring whether L2 pragmatic features can be acquired without any instructional intervention; however, the total volume of research in this area is well below that for mainstream SLA. A few ILP studies have examined the efficacy of certain instructional methods and tried to address the issues of teachability, but these have failed to answer directly the question of how the nature of input enhancement influences the development of L2 pragmatic competence.

The present study is an attempt to address this rather ignored issue by examining the effect of two forms of explicit instruction namely, form-comparison and direct teaching of formulas on giving compliments in English in a foreign language context.

\section{BACKGROUND OF THE STUDY}

\section{A. Research on Speech Acts}


Speech act research has, to a large extent, been represented in cross-cultural and interlanguage pragmatics research. Studies in this respect have shown that even grammatically- advanced learners show differences from target-language pragmatic norms. In other words, a learner of high grammatical proficiency will not necessarily possess concomitant pragmatic competence.

In a paper, Bardovi-Harlig (2001) outlines four ways in which learners (nonnative speakers NNSs) can differ from native speakers (NSs) in production of speech acts:

a. Choice of speech acts: NNSs may perform different speech acts than NSs in the same contexts, or, alternatively, they may elect not to perform any speech act at all. The best examples of this come from authentic conversations and role-plays where speakers have some flexibility in determining what they will say or do. For example, in a role-play designed by Cohen and Olshtain (1993), a scenario was designed to elicit an apology. In the scenario the learner was supposed to meet a friend of his at his friend's house to study. The learner came half an hour late and thus had to apologize for being late. The learner, however, thought that in the scenario the condition for an apology was not met and refused to offer an apology. In other words, he thought that an appointment with another student to study was not very important and keeping someone waiting at his or her own house was not a very serious offense.

b. Semantic formulas: A second way in which NSs and NNSs may differ is the choice of semantic formulas. Semantic formulas represent the means by which a particular speech act is accompanied in terms of the primary content of an utterance. For example, an apology may contain an illocutionary force indicating device (I'm sorry), an explanation or account of the situation (e.g., the bus was late), an acknowledgement of responsibility (e.g., It's my fault) an offer of repair (e.g., I'll pay for the broken vase), and/or a promise of forbearance (e.g., It won't happen again).

With regard to this, in a study of complaint, Murphy and Neu (1996) also found a difference in the use of semantic formulas, or what they called "semantic components". The NSs, fourteen American men, and the NNSs, fourteen Korean men, all of whom were graduate students, completed an oral discourse completion task in which they were asked to assume the role of a student whose assignment was unfairly graded by his professor. The NSs and NNSs showed relatively high agreement on three of the four semantic formulas used to realize the complaints. All of the subjects except one of the NNSs began the complaint with an explanation of purpose as in examples (1) and (2) below:

(1)Uh, Dr. Smith, I just came to see if I could talk about my paper. (NS)

(2)Good afternoon, professor. Uh, I have something to talk to you about my paper...(NNS, L1 Korean)

Respondents also showed relatively high agreement on the use of the justification and solution formulas. However, NSs and NNSs differed noticeably on the formula which constitutes the head act.

c. Content. A third way in which NSs and NNSs may differ is the content of their contribution. Whereas a semantic formula names the type of information given, content refers to the specific information given by a speaker. Even in cases where NSs and NNSs use the same semantic formulas, the content that they encode can be strikingly different (Takahashi and Beebe, 1987).

A case in point is the content of explanations, a semantic formula found in refusals. In a comparison of the explanations offered by American and NSs of Japanese using English, Beebe, Takahashi and Uliss-Weltz (1990) characterized the explanation of the American as providing more details and the explanation of the Japanese as being vague by the American norm. When refusing an invitation, for example, an American might say 'I have a business lunch that day', whereas a Japanese speaker might say 'I have something to do'.

d. Form. The fourth way in which NNS production may differ from the NS norm is the form of a speech act. For example, in giving suggestions NSs might say 'I was thinking of taking a trip', whereas NNSs, in the same situation, are more likely to say so, 'I just decided on taking a trip for the summer', making the suggestion rather bizarre in terms of American norms.

With regard to compliments, a seminal paper by Wolfson and Menes (1980) on compliments provided the first comprehensive description on the formula city of compliments in American English. They found that a narrow range of syntactic formulas accounted for the majority of observed compliments, with the majority (97.2\%) of their corpus of 686 naturally occurring compliments falling into one of the following nine syntactic formulas:

1. NP (is, looks) (really) ADJ (pp)

2. I (really) (like, love) NP

3. PRO is (really) (a) (ADJ) NP

4. You V (a) (really) ADJ NP

5. You V (NP) (really) ADV (pp)

6. You have (a) (really) ADJ NP

7. What (a) (ADJ) NP!

8. ADJ (NP)!

9. Isn't NP ADJ!

An interesting point about the formula city of compliment is the facts that, as Wolfson and Manes admit, the top three syntactic formulas accounted for some $85 \%$ of all compliments in American English. The nine syntactic formulas described by Manes and Wolfson provide a useful, if not comprehensive, overview of the pragma-linguistic recourses in American English.

\section{B. The Effect of Instruction in Developing Pragmatic Competence}


The research that has been done to date does indicate that pragmatic development can be facilitated by instruction, particularly when that instruction is of an explicit nature (Kasper, 1992). Research has shown that learners who have received no specific instruction in L2 pragmatics have noticeably different L2 pragmatic system than NSs of the L2.

For instance, Kenneth and Connie (2001) report the result of a study which compared the effects of inductive and deductive approaches to the teaching of English compliments and compliment responses to university-level learners of English in Hong Kong. There were three groups in all- a deductive group, an inductive group, and a control group. Both treatment groups received instruction in the target speech acts, but while the deductive group was provided with metapragmatic information through explicit instruction before engaging in practice activities, the inductive group engaged in pragmatic analysis activities in which they were expected to arrive at the relevant generalizations themselves. The results from a discourse completion task showed a marked increase in the use of compliment formulas by both treatment groups, with no similar increase for the control group. Results from compliment responses revealed a positive effect only for the deductive group, indicating that although inductive and deductive instruction may both lead to gains in pragma-linguistic proficiency, only the latter may be effective for developing socio-pragmatic proficiency.

In a similar research, Takahashi (2001) examined the effects of input enhancement on the development of English request strategies by Japanese EFL learners at a Japanese university using four input conditions, namely, explicit teaching, form comparison, form search, and meaning focused conditions. The explicit teaching condition manifested the highest degree of input enhancement and the meaning focused condition the least. The results indicated that the degree of input enhancement influenced the acquisition of request forms, explicit teaching having the strongest impact. The explicit instruction helped the learners both develop their pragmatic competence and enhance their confidence in performance to a greater extent than the three implicit conditions, and the self report data also showed that the formsearch and the meaning focused conditions equally failed to draw the learners' attention to target forms in the input.

These studies along with similar research on pragmatics acquisition put emphasis on the fact that providing metapragmatic information with the target features is most likely to advance the learners' L2 pragmatic competence.

\section{RESEARCH QUESTIONS AND HYPOTHESES}

As noted earlier, research on teaching pragmatics has overwhelmingly given support to the explicit teaching of pragmatics. A question which, we believe, needs further investigation is what kind of explicit teaching is more effective for teaching pragmatics in an acquisition-poor context (i.e., English as a foreign language context). Accordingly, the researchers posed the following three questions:

1. Do Iranian learners of English have a different notion of choice of speech act with regard to giving compliments?

2. Do Iranian learners of English benefit from instruction in giving compliments in a foreign language context?

3. Are there differential effects of instruction for form- comparison and explicit teaching approaches (two forms of input enhancement) to the teaching of giving compliments in a foreign language context?

\section{METHOD}

\section{A. Participants}

The participants in this study were 38 Iranian college students at the Azad University of Kermanshah, the majority of whom were females. They were all English students who had been studying English at the university for three and a half years with a mean age of 23. The participants made up two intact classes, taught by the researchers, which were randomly assigned to two groups, namely experimental group (20 students), and a control group (18 students). The participants had different levels of language proficiency. Another individual participant providing the compliment expressions was Joshua who was born in America and lived there for twenty years (He was born in America from an Iranian father and an American mother but for some personal reasons came to live with his father in Kermanshah, Iran).

\section{B. Design}

A quasi-experimental, pretest/posttest design was adopted for the purposes of this study. Because of the large sample size, discourse completion tests (DCTs) were employed to elicit the main data in the pretest and posttest sessions. The participants were also required to indicate, in the pretest, whether they considered the given situations requiring compliment or not.

\section{Selection of the Compliment Situations}

Fourteen compliment scenarios were adopted. These scenarios were mainly derived from a preliminary questionnaire administered to fifteen Cantonese-speaking undergraduate students in Hong Kong by Kenneth and Connie (2001) in their study ${ }^{*}$. The questionnaire involved a type of exemplar generation in which participants were given a sheet of paper illustrating a compliment in English and asked to provide the most appropriate compliment for each of them. These situations were chosen in terms of the following principles: first most frequently recurring scenarios were chosen;

\footnotetext{
* Some situations were slightly modified to suite the students' level.
} 
second, scenarios incorporating a range of interlocutors from two contexts (family and school) were chosen; and third, a range of the most frequently occurring compliment topics was presented.

\section{Pretest and Posttest}

The pretest DCT contained 14 situations. The situational descriptions were given in English. The participants were asked to provide appropriate compliment expressions for each situation. For each situation, the DCT was provided. In order to eliminate the pretest effect on the treatment, the posttest was administered one week after the treatment. Below are two examples from the DCT:

Situation 1: Alex (one of the sons) is a business major. He has an interview today for a part-time job with a large investment company, so he is wearing his best suit. Do you compliment him on his appearance? If yes, what would you say to compliment on his appearance?

You:

Situation 2: You have just finished having dinner at home that was prepared by Mrs. White (the mother). Do you compliment her on it? If yes, what would you say to compliment her on the meal?

You:

\section{E. Materials and Procedures}

Two intact classes took part in this study, each of which was randomly assigned to two groups and (i.e., one experimental and one control group). The control group received Form-Comparison instruction on giving complements and the experimental group received explicit instruction on giving compliments based on the formulas proposed by Wolfson and Manes (1980). The treatments consisted of six lessons lasting for approximately 30 minutes each. Instruction began right at the beginning of the summer term in 2010 and continued until the end of the term (4 weeks). Content for both instructed group was identical, and was based on findings from the literature on giving compliments. All the instruction was carried out by the researchers who also taught the main course.

For the experimental group (explicit instruction), two types of treatment materials were prepared for each session. One was handouts in which detailed pragmalingustics information (i.e., formulas presented by Wolfson and Manes, 1980) was provided. The situations were explained in English, and then the appropriate formula(s) were presented. The students had to practice the formula(s) in similar situations. Examples and detailed information about when and where to use each formula was also presented by the researchers (i.e., the instructors) for the explicit group.

For the other control group (i.e., form comparison group) a different way of presentation of compliments was provided by the researchers. First, in each session, the participants were presented with the same situations given to the experimental group. Then, they were asked to give their own compliments in English. After this, the researchers provided the compliments produced by native speakers for the given situations (For both groups, the situations were drawn from a variety of books usually taught in Iran, including Person to Person series, Interchange series, and East West series). Finally, the participants were required to compare their own English compliment expressions with those supplied by NSs in the corresponding situations in order to discover any differences in compliment realization patterns. This again included six sessions each lasting 30 minutes.

\section{DATA ANALYSIS AND RESUlTS}

The data collected for this study were analyzed both qualitatively and quantitatively. Qualitatively, the data gained from the DCT showed that the learners considered all the presented situations as requiring compliments. In other words, it was shown that Iranian learners of English did not differ from native speakers of English as far as choice of the speech act is concerned. In the pretest, eighteen situations requiring compliments were presented (see the Appendix), and the participants in all the two groups were asked to say whether the situations needed compliments or not. All the participants agreed that the scenarios required giving compliments. This is an interesting and important point in that no cultural differences are seen between the two languages (i.e., English and Farsi) in so far as the choice of speech act is concerned.

In order to judge the compliments produced by the learners in the two groups, the researchers had Joshua assess them in terms of acceptability of the compliments. It was found that nearly all the compliments produced by the Iranian learners of English in the pretest were heavily influenced by the participants 'first language (i.e., Farsi) indicating that their pragmatic competence was not developed hand in hand with their grammatical competence. In this case, pragmatic knowledge had a negative outcome in that their production of compliments did not match those of the NNSs'.

For the post tests, the same pretest was given to the participants in both groups. They were also judged by Joshua (the native speaker participant of the study). After calculating the mean score of each group, a t-test was run to determine whether the difference was significant or not. The result of the t-test is presented below. The result showed that the experimental group receiving the explicit instruction outperformed the control group taught by form comparison procedure. 
TABLES $1 . \& 2$

MEAN AND STANDARD DEVIATION OF DCT COMPLIMENTS

\begin{tabular}{|c|c|c|c|c|c|}
\hline & GROUP & $\mathrm{N}$ & Mean & Std. Deviation & Std. Error Mean \\
\hline \multirow[t]{2}{*}{ Scores } & 1 & 18 & 10.1667 & 5.32618 & 1.25539 \\
\hline & 2 & 20 & 11.1350 & 5.86105 & 1.31057 \\
\hline
\end{tabular}

\begin{tabular}{|l|l|l|l|l|l|l|l|}
\hline & $\begin{array}{l}\text { Levene's test for } \\
\text { equality of varience }\end{array}$ & & & & & & \\
\hline & F & Sig. & T & df & sig.2-tailed & Mean diff & Std. Error difference \\
\hline Equal variance assumed & .228 & .636 & -.531 & 36 & .599 & -.96833 & 1.82422 \\
Equal variances not assumed & & & -.534 & 35.994 & .597 & -.96833 & 1.81483 \\
\hline
\end{tabular}

\section{DISCUSSION AND CONCLUSION}

This study set out to answer three questions. The first question concerned whether Iranian learners of English have a different notion of choice of speech with regard to giving compliments. The second concerned whether learners benefited from instruction in giving compliments in a foreign context. The third sought to determine whether the kind of input enhancement (explicit or form comparison procedure) have better effects on the development of pragmatic competence, with the target features being giving compliments.

The answer to the first question seems to be negative; all the NNSs participating in the study agreed that the presented scenarios needed giving compliments. This can have significance in cross-cultural research in the sense that speech act research has, to a great extent, been represented in cross-cultural and inter language pragmatics research. With regard to the cross-cultural research, Chick, (1996) argues that sociolinguists have traced the sources of intercultural miscommunication to the distinctive nature of value system, pervasive configurations of social relations, and dominant ideologies of cultural groups. Such dimensions of the social context shape communicative conventions. Similarly Wolfson (1992), holds that what members of particular cultural groups thank or apologize for, or compliment on, usually reflects values because in performing these speech acts, people are often implicitly assessing the behavior, possessions, accomplishments, character, or appearances of others She also traces the high frequency of complimenting that she found among status-equal friends, coworkers, and acquaintances in middle-class urban American society to the configuration of social relations in that society.

The answer to the second question, to us, is positive in that the two groups had a much better performance in the posttest. This can also be beneficial in that speech acts reflect, for the most part, routinized language behavior. This potential is usually overlooked in a foreign language context where learners have difficulty access to input. In response to the third question, however, the DCT results for compliment responses revealed a more positive effect only for the explicit group, indicating that although explicit and form comparison instruction may both lead to gains in pragmalingustics proficiency, only the former may be effective for developing socio- pragmatic proficiency. This may be the result of the highly formulaic nature of American English compliments.

The above findings are probably useful for teachers to help learners develop their pragmatic competence by first identifying where they might have problems in performing speech acts. This can be carried out through different procedures from discourse completion tasks to role plays, and to acceptability judgments. Also, teachers can embark on giving the routines of performing speech acts emphasizing the formulas commonly used in these situations. Learners may be required as well to perform the presented speech acts through role plays in which they have to assume different roles and relationships with their interlocutors. Other procedures, of course, could be utilized but role plays can be more beneficial because in role plays learners have to process the language syntactically and adjust themselves to the roles assigned to them. Finally, feedback and discussion can be useful in teaching speech acts in the sense that students can benefit from the feedback given by their teachers and peers.

\section{LIMITATIONS OF THE STUDY}

There are a number of potential problems with this study that require caution in making claims of any kind. The learners who took part in the study were almost pre-intermediate in terms of English proficiency. Different results might have been gained, had the participant been advanced with regard to their English proficiency. The other problem has to do with the discourse completion task procedure used in the study, since it is often not possible to measure instructional effects through the use of written questionnaires. Put simply, questionnaires are indirect measures in that the data resulting from responses to questionnaires are not the result of direct observation. In sum, then, this study has provided some tentative evidence that explicit procedures in enhancement continuum can make a difference in a foreign language context. Last but not least, only two aspects of compliments (how to give compliments as well as the choice of speech act) have been examined. A comprehensive study might include both giving and responding to compliments. 
1. Alex (one of the sons) is a business major. He has an interview today for a part time job with a large investment company. So he is wearing his best suit. What do you to compliment him on his appearance?

2. You have just finished having dinner at home that was prepared by Mrs. White (the mother. You compliment her on the meal.

3. You are at the university, and class has just ended. You overhear John answering his classmate's question about how to use the computer. You compliment him on it.

4. Your brother has just bought a new cell phone. You compliment him on it.

5. It's afternoon, and you go Jeff's (your student) house to help him study math. He is dressed in his best clothes. You compliment him on his appearance.

6. You are at the university, and class has just ended. Your classmate gave a good presentation in class, and you compliment her or him on it.

7. You go to Jeff's house (your student) to help him study math. You notice that he has a new pencil case, and compliment him on it.

8. You see Alex (one of the sons) swimming well. You compliment him on his ability.

9. Mrs. White and her mother, Mrs. Bush, have just returned from shopping. Mrs. Bush bought a new handbag, and you compliment her on it.

10. You are at the university, and the class has just ended. While you are putting your books away, you see Michael, one of your classmates wearing a new suit. You compliment him on it.

11. Sue (the daughter) went shopping and bought some jewelry. You see that she is wearing a new ring. You compliment her on it.

12. You go top Jeff's (your student) house to help him study math. He tells you he got an 'A' on his last exam. You compliment him.

13. Jeff (your student) has gone to a hair salon to cut his hair short. You see him with a good hair style. Do you compliment him on it? If yes, what do you say?

14. You have gone to a party. Michael (your friend) sings a song well. Do you compliment him on it? If yes, what would you say?

\section{REFERENCES}

[1] Bardovi-Harlig, K. (2001). Evaluating the empirical evidence: grounds for instruction in pragmatics? In Kenneth, R. \& Kasper, G. Pragmatics in Language Teaching (pp.13-33).

[2] Beebe, L., Takahashi, T. \& Uliss-Weltz, R. (1990). Pragmatic transfer in ESL refusals. In R. Scarcella, E. Anderson, \& S. Krashen (Eds.), Developing Communicative Competence in a Second Language (pp. 55-73).

[3] Cohen, A. D. \& Olshtain, E. (1993). The production of speech acts by EFL Learners. TESOL Quarterly, 27 (1), 33-56.

[4] Chick, J. k. (1996). Intercultural Communication. In Kenneth, R. \& Kasper, G. Pragmatics in Language Teaching (pp. 329348).

[5] Kasper, G. (1992). Pragmatic transfer. Second language Research, 8, 203-231.

[6] Kenneth, R. \& Connie Ng. (2001). Inductive and deductive teaching of compliments and compliment responses. In Kenneth, R. \& Kasper, G. Pragmatics in Language Teaching (pp. 145-171).

[7] Murphy, B. \& Neu, J. (1996). My grade's too low: The speech act set of complaining. In Susan M. Gass \& Joyce Neu (Ed.): Speech acts across cultures: Challenges to communication in second language (191-216).

[8] Schmidt, R. (1990). The role of consciousness in second language learning. Applied Linguistics, 11(2), 129-58.

[9] Sharwood S. M. (1993). Input Enhancement in Instructed SLA. Studies in Second Language Acquisition, 15, pp 165-179.

[10] Takahashi, S. (2001). The role of input enhancement in developing pragmatic competence. In Kenneth, R. \& Kasper, G. Pragmatics in language teaching (pp. 171-200).

[11] Takahashi, T. \& Beebe L.M. (1987). The development of pragmatic competence by Japanese learners of English. JALT Journal, $8,131-155$

[12] Wolfson, N., \& Manes, J. (1980). The compliment as a social strategy. Papers in Linguistics, 13, 389-410.

[13] Wolfson, N. (1992). Intercultural communication and the analysis of conversation. In R. K. Herbert (Ed.), Language and Society in Africa (pp. 197-214).

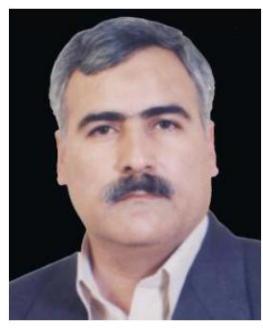

Hossein Vahid Dastjerdi (b. 1955, Isfahan, Iran) teaches in the English Language Department at the University of Isfahan, Iran. He is associate professor of applied linguistics and has taught courses of variegated character, including translation courses, for years. He has been a fellow of the English Centers at the universities of Isfahan and Shiraz where he has investigated into issues related to materials preparation for GE. and ESP. courses. He is the author of a number of books in this respect. He has also published a good number of articles on discourse, testing and translation in local and international journals.

Dr. Vahid's current research interests include testing, materials development, translation, the metaphoricity of language, discourse analysis, pragmatics and critical discourse analysis. He is presently involved in a number of projects concerning translation studies as well as figurative language use. 


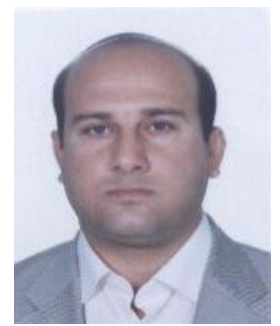

Majid Farshid (b. 1974, Kermanshah, Iran) is currently a Ph. D. candidate at the University of Isfahan, Isfahan, Iran. He received his M.A. in TEFL at Allameh Tabatabee University of Tehran (2003) following the completion of his B.A. in English Teaching from Razi University of Kermanshah, Iran (2000). His main research areas of interest are: Second Language acquisition, Language Teaching Methodology, Discourse Analysis and Pragmatics. He has been working as an EFL instructor since 2000. 